\title{
Cytomegalovirus (CMV) Infection in Infants: Two Case Reports and Review of Literature
}

\author{
Zeti N.S $S^{a, b}$, Norjihan A.H, ${ }^{a, b}$, Nabilah A. ${ }^{a, b}$, Alwi MB ${ }^{b, c}$, Mohd Zulfakar M. ${ }^{b, d}$, Suharni M. ${ }^{b, e}$ \\ ${ }^{a}$ Department of Medical Microbiology and Parasitology, Health Campus, USM, 16150, Kubang Kerian, Kelantan, Malaysia. \\ ${ }^{b}$ Hospital USM, Health Campus, USM, 16150, Kubang Kerian, Kelantan, Malaysia. \\ 'Department of Internal Medicine, Health Campus, USM, 16150, Kubang Kerian, Kelantan, Malaysia. \\ ${ }^{d}$ Department of Anaesthesiology and Intensive Care, Health Campus, USM, 16150, Kubang Kerian, Kelantan, Malaysia. \\ ${ }^{e}$ School of Dental Sciences, Health Campus, USM, 16150, Kubang Kerian, Kelantan, Malaysia.
}

\author{
Keywords \\ Cytomegalovirus (CMV), infants, jaundice, \\ cataract, congenital infection \\ Corresponding Author \\ Zeti Norfidiyati Ayub \\ Department of Medical Microbiology and \\ Parasitology, School of Medical Sciences, \\ University Sains Malaysia Health Campus, \\ 16150, Kubang Kerian, Kelantan, Malaysia. \\ Tel No: +609-7676286. \\ E-mail: norfidiyatiz@yahoo.com. \\ Received: 31 May 2020; Accepted: 31 \\ January 2021 \\ Doi: https://doi.org/10.31436/imjm.v20i3
}

\begin{abstract}
Cytomegalovirus (CMV) is a virus under the Herpesviridae family. We describe two case reports on different manifestations of infants with CMV infection presented with neonatal jaundice, small for gestational age (SGA) and congenital cataract. Congenital CMV (cCMV) was diagnosed in a neonate presented with jaundice and SGA. cCMV cannot be excluded in another case as no CMV PCR done within 3 weeks of life. Only one cCMV infection was treated with 6 weeks of ganciclovir anti-viral therapy, which presented with neonatal jaundice, SGA with a very high CMV viral load. All cases were under multidisciplinary followup, including pediatric for developmental assessments, audiologist for hearing assessment, and ophthalmology for vision assessment. These case reports describe the importance of thorough clinical examination and early screening of CMV infection in infants to rule out cCMV as CMV is the commonest congenital treatable viral infection in Malaysia. Early treatment and intervention can be planned for child wellbeing.
\end{abstract}

\section{INTRODUCTION}

Cytomegalovirus (CMV) is a common virus that causes morbidity and mortality worldwide. A preliminary study done at the Institute of Medical Research (IMR) Malaysia showed that 37 out of 125 asymptomatic pregnant women who tested positive with anti-CMV IgM and IgG had obstetric complications such as intrauterine death and fetal anomalies.1 Another preliminary study among 79 volunteers in Wilayah Persekutuan and Selangor showed a $92 \%$ seroprevalence of CMV.2 Among 1688 infants with congenital abnormalities, positive anti-CMV IgM was found in 193 infants (11.4\%), significantly higher than the prevalence of congenital syphilis, rubella, HSV, and toxoplasmosis. ${ }^{3}$

Screening of CMV infection in infants is important as it is a non-genetic cause of sensorineural hearing loss
(SNHL) and neurodevelopmental delay worldwide. ${ }^{4}$ According to a guideline by the Ministry of Health Malaysia 2014, in-utero infection such as CMV needs audiological assessment to detect the presence of hearing loss. ${ }^{5}$ This recommendation is in line with the World Health Organization (WHO) policy on the universal hearing assessment that has to be adopted in all countries with rehabilitation supports. ${ }^{6}$

\section{CASE 1}

A 2-month-old baby girl delivered prematurely at 35 weeks of gestational age with the birth weight of $2-\mathrm{kg}$ initially presented with neonatal jaundice at 80 -hours of life requiring intensive phototherapy. She was found small for her gestational age with no 
hepatosplenomegaly. Her neurological examination was unremarkable. Her parent has group B blood. Her TSH level was normal. G6PD screening was negative. Direct Coomb's test was negative. Investigations for toxoplasma, rubella, cytomegalovirus, and herpes (TORCHES) gave positive Toxoplasma IgG and CMV IgG antibodies with negative IgM for both. Repeated toxoplasma $\operatorname{IgG}$ in 2-weeks-time showed no four-fold increase in $\operatorname{IgG}$ titer and therefore excluding toxoplasma infection in this baby. Her CMV DNA quantitative result at two days of life was $8029 \mathrm{IU} / \mathrm{ml}$. Eye assessment showed no retinitis, and her neonatal hearing assessment was normal. Ultrasound brain and cranium showed bilateral intraventricular hemorrhage Grade I with no evidence of intracranial calcification. Her mother is a 25-year-old lady with mild anemia in pregnancy. Her mother was asymptomatic during pregnancy, and delivery with TORCHES screening showed positive toxoplasma and CMV IgG with negative IgM. After two months, the repeated CMV DNA quantitative result of the baby girl was $776 \mathrm{IU} / \mathrm{ml}$ after 6-weeks of ganciclovir anti-viral therapy. She was currently on follow-up for developmental and hearing assessment under a university hospital in Kuala Lumpur due to logistic reasons.

\section{CASE 2}

A 4-month-old boy, delivered full term with the birth weight of $2.26 \mathrm{~kg}$ with asymmetrical small for gestational age (SGA), a referred case from a health clinic for bilateral eye cataract possibly due to intrauterine infection. No history of trauma or eye discharge before. He is the youngest out of four siblings. His mother had a history of bilateral eye cataract operated at 10 years old and currently on the aphakic glass with no maternal syndromic facies documentation. No genetic screening was done on the mother, and no history of maternal prolonged steroid usage. Antenatally and postnatally uneventful, his mother had no history of fever with rashes during pregnancy. Physical examination showed that he had microcephaly, rotatory nystagmus, bilateral eye cataract with hypotonia. His TORCHES screening revealed positive CMV IgM, CMV IgG (titre: $8.42 \mathrm{U} / \mathrm{ml}$ ) with CMV DNA viral load at four months of age was 756 $\mathrm{IU} / \mathrm{ml}$. He underwent examination under anesthesia
(EUA), followed by lens aspiration for both eyes. Intraoperatively noted the presence of persistent fetal vasculature in his left eye. He was discharged well oneday post-operation and referred to a vitreoretinal surgeon at the nearby government hospital for an expert opinion. His mother refused for CT-scan brain but keen for USG brain and cranium. USG brain and cranium was planned, but due to logistic reasons, the date was re -scheduled. As there was no active infection, he was not started on any anti-viral therapy and is currently monitored under pediatric, ophthalmology, and hearing follow-up.

\section{DISCUSSION}

Cytomegalovirus is a double-stranded DNA virus, usually causing asymptomatic infection or mild flu-like illness that may remain latent throughout life and reactivate later. 7 The mode of transmission of CMV is via sexual, vertical, perinatal, parenteral, and direct contact with saliva or breast milk. ${ }^{8}$ In pregnancy, the transmission of CMV can occur in primary infection, reinfection with a new strain, or reactivation of latent infection. ${ }^{9}$ The transmission risk is the greatest in the third trimester of pregnancy, whereas the risk of severe complications is the greatest in the first trimester. ${ }^{9}$

The rates of congenital infection in developed countries are about $0.6-0.7 \%$ of live births, whereas, in the developing world, higher rates between 1-5\% have been observed. ${ }^{10,11}$ In Malaysia, out of 193 congenital CMV (cCMV) infections, $10.4 \%$ presented with CNS defects. ${ }^{3}$ According to CDC updated $31^{\text {st }}$ of May 2019, cCMV is diagnosed within 3 weeks after birth by molecular test, CMV DNA detection in the urine, saliva or blood ${ }^{9}$ as detection of CMV DNA after that may be due to infection acquired during or after delivery. In our case, the patient diagnosed with congenital CMV presented with early-onset jaundice post-delivery, in which CMV PCR was done at two days of life. In the second case, congenital CMV infection still cannot be rule out as no CMV PCR was done within 3 weeks of life.

The majority of children (85-90\%) with cCMV are asymptomatic and therefore not diagnosed at birth. ${ }^{12}$ Even though only $10 \%$ of cCMV infants were symptomatic, the mortality rate in symptomatic infants 
can increase to up to $20-30 \% .{ }^{13}$ Congenital CMVinfected infants can present with microcephaly, prolonged jaundice, retinitis, cataract, thrombocytopenia, or hepatosplenomegaly. 14 Symptomatic infants with cCMV had higher amounts of CMV DNA in urine and peripheral blood than asymptomatic infants at birth. ${ }^{15}$ In these two cases, we can see that CMV viral load is detectable in all these symptomatic children but highest in confirmed cCMV cases. Identifying cytomegalovirus or its antigen in infants after two to three weeks of life may represent perinatal or postnatal infection even though congenital infection cannot be ruled out. ${ }^{16}$

Concurrent toxoplasma and CMV infection have been reported before in the literatures among newborn babies and immunocompromised host. ${ }^{17,18}$ Even though toxoplasma $\operatorname{IgG}$ was detected in the first case, a significant four-fold increment of IgG titer was not reported from the second sample in 2-weeks time. Previous literatures showed that the presence of Toxoplasma IgG titer in a newborn without significant four-fold increment could be due to passive transfer of maternal toxoplasma IgG from the placenta. ${ }^{19,20}$

In terms of clinical presentations, bilateral cataracts are commonly due to several causes, such as TORCH infection and prematurity, seen in the second patient. ${ }^{21}$ CMV viral load is important before starting preemptive therapy and after completed treatment for monitoring response to therapy. ${ }^{22,23}$ Bear in mind that the presence of CMV end-organ disease does not always correlate with CMV viremia. In the second case, even though the mother had a history of operated bilateral childhood cataract, no genetic screening done before with no syndromic facies or history of prolonged steroid usage that has ruled out the causes of bilateral cataract. 24

Early treatment has been proven to prevent sensorineural hearing loss later in life in CMV infection among children. 4 There are several studies on ganciclovir (GCV) usage and oral valganciclovir (VGCV) for cCMV patients. A study in 2003 showed that $6 \mathrm{mg} / \mathrm{kg} /$ dose GCV therapy intravenously two times daily for 6-weeks improves hearing outcomes at 6 -months. ${ }^{25}$ Another study using GCV prodrug (oral valganciclovir) showed that $16 \mathrm{mg} / \mathrm{kg} /$ dose twice daily has a comparable systemic effect with intravenous GCV and gives oral treatment an options. ${ }^{26} \mathrm{~A}$ comparison study using oral VGCV twice daily for 6-weeks of 16 $\mathrm{mg} / \mathrm{kg} /$ dose versus 6-months showed that 6-months of therapy has better improvement in hearing and developmental outcomes in the longer term. ${ }^{27}$ Lower risk of neutropenia observed in valganciclovir therapy in comparison to ganciclovir therapy. ${ }^{27}$

Several PCR methods are available for CMV viral load detection, such as Cobas AmpliPrep/Cobas TaqMan CMV test (Cobas CMV) (Roche Diagnostics, Indianapolis, IN) approved in 2012, Abbott RealTime CMV DNA Quantitative Assay approved five years later in 2017 by United State Food and Drug Administration (US-FDA), Q-CMV real-time complete kit (Nanogen Advanced Diagnostic S.r.L., Italy) and etc.

We are currently using RealStar ${ }^{\circledR}$ CMV PCR Kit 1.0 for CMV DNA quantitative assay, which accepts peripheral blood specimens. In the future, we may use kit that allows for detection and quantification of CMV DNA on urine and saliva samples, preferably in infants of less than 3 weeks of age. We strongly suggest CMV viral load early, preferably within two to three weeks of life, particularly in symptomatic infants, to rule out cCMV infection.

\section{CONCLUSION}

In conclusion, both cases are symptomatic CMV infections in infants with detectable viral load. It is important to do a thorough clinical examination and to screen newborn babies within 3-weeks of life to rule out congenital CMV infection. Early treatment and rehabilitation interventions can improve CMV longterm sequelae, such as hearing and neurodevelopmental disabilities.

\section{ACKNOWLEDGEMENT}

This study is funded by Research University Grant, Universiti Sains Malaysia, under the Ministry of Higher Education (MOHE) with grant no: (1001/ PPSP/8012293). We express our gratitude to our hospital director for his permission to use medical records and hospital equipment during this manuscript's completion process.

IMJM Volume 20 No.3, July 2021 


\section{REFERENCES}

1. Saraswathy, T. S., Az-Ulhusna, A., Asshikin, N., Suriani, S. \& Zainah, S. RESEARCH NOTE SEROPREV ALENCE OF CYTOMEGALOVIRUS INFECTION IN PREGNANT WOMEN AND ASSOCLATED ROLE IN OBSTETRIC COMPLICATIONS: A PRELIMINARY STUDY.J trop Med public bealth vol. 320 (2011).

2. Camalxaman, S. N., Zeenathul, N. A., Quah, Y. W., Zuridah, H. \& Loh, H. S. New Estimates of CMV Seroprevalence in Malaysia. Where Do We Go From Here? Med J Malaysia vol. 67 (2012).

3. Balasubramaniam, V., Sinniah, M., Tan, M. D. S. K., Redzwan, G. \& Lo'man, S. G. The Role of Cytomegalovirus (CMV) Infection in Congenital Diseases in Malaysia. (1994).

4. Marsico, C. \& Kimberlin, D. W. Congenital Cytomegalovirus infection: Advances and challenges in diagnosis, prevention and treatment. Italian Journal of Pediatrics vol. 43 (2017).

5. Ministry of Health, M. MINISTRY OF HEALTH MALAYSLA GUIDELINES FOR NEON ATAL HEARING SCREENING. https://www.moh.gov.my/moh/resources/ Penerbitan/PErkhidmatan Pembedahan KKM/ GUIDELINES_FOR_NEONATAL_HEARI NG_SCREENING_PROGRAM_-.pdf (2014).

6. World Health Organization (WHO). Newborn and infant hearing screening CURRENT ISSUES AND GUIDING PRINCIPLES FOR ACTION WHO Library Cataloguing-in-Publication Data Newborn and infant hearing screening: current issues and guiding principles for action. https://www.who.int/ blindness/publications/

Newborn_and_Infant_Hearing_Screening_Rep ort.pdf (2009).

7. Kauser, A. \& Todd S Wills. Cytomegalovirus (CMV): Practice Essentials, Background, Pathophysiology. Medscape https:// emedicine.medscape.com/article/215702overview (2018).

8. CDC. CMV | Clinical Features for Healthcare Professionals | Cytomegalovirus | CDC. https://www.cdc.gov/cmv/clinical/ overview.html (2020).
9. Centers for Disease Control and Prevention. Congenital CMV Infection I CDC. https:// www.cdc.gov/cmv/clinical/congenitalcmv.html.

10. Manicklal, S., Emery, V. C., Lazzarotto, T., Boppana, S. B. \& Gupta, R. K. The 'Silent' global burden of congenital cytomegalovirus. Clin. Microbiol. Rev. 26, 86-102 (2013).

11. Cannon, M. J. Congenital cytomegalovirus (CMV) epidemiology and awareness. Journal of Clinical Virology vol. 46 (2009).

12. Arav-Boger, R., Foster, C. B., Zong, J. \& Pass, R. F. Human Cytomegalovirus-Encoded $\alpha$ Chemokines Exhibit High Sequence Variability in Congenitally Infected Newborns. J. Infect. Dis. 193, 788-791 (2006).

13. Dollard, S. C., Grosse, S. D. \& Ross, D. S. New estimates of the prevalence of neurological and sensory sequelae and mortality associated with congenital cytomegalovirus infection. Rev. Med. Virol. 17, 355-363 (2007).

14. Swanson, E. C. \& Schleiss, M. R. Congenital Cytomegalovirus Infection. New Prospects for Prevention and Therapy. Pediatric Clinics of North America vol. 60 335-349 (2013).

15. Boppana, S. B. et al. Congenital cytomegalovirus infection: Association between virus burden in infancy and hearing loss. J. Pediatr. 146, 817-823 (2005).

16. A. Ross, S., Novak, Z., Pati, S. \& B. Boppana, S. Overview of the Diagnosis of Cytomegalovirus Infection. Infect. Disord. - Drug Targets 11, 466474 (2012).

17. De Zegher, F. et al. Concomitant cytomegalovirus infection and congenital toxoplasmosis in a newborn. Eur J Pediatr vol. 147 (1988).

18. Kuruppu, D. K., Giuliari, G. P. \& Mackay, D. D. Concurrent cerebral toxoplasmosis and cytomegalovirus retinitis in a patient with human immunodeficiency virus. Can. J. Ophthalmol. 54, e33-e35 (2019).

19. Thangarajah, P. et al. Usefulness of paired samples for the Serodiagnosis of toxoplasmosis infection in a tertiary teaching Hospital in Malaysia. BMC Infect. Dis. 19, (2019).

20. Pomares, C. \& Montoya, J. G. Laboratory diagnosis of congenital toxoplasmosis. Journal of Clinical Microbiology vol. 54 2448-2454 (2016). 
21. Medscape. Congenital Cataract: Background, Pathophysiology, Epidemiology. 17th angust https://emedicine.medscape.com/ article/1210837-overview (2018).

22. Tan, S. K., Waggoner, J. J. \& Pinsky, B. A. Cytomegalovirus load at treatment initiation is predictive of time to resolution of viremia and duration of therapy in hematopoietic cell transplant recipients. J. Clin. Virol. 69, 179-183 (2015).

23. Razonable, R. R. \& Hayden, R. T. Clinical utility of viral load in management of cytomegalovirus infection after solid organ transplantation. Clinical Microbiology Reviews vol. 26 703-727 (2013).

24. Khokhar, S. et al. Pediatric cataract. Indian Journal of Ophthalmology vol. 65 1340-1349 (2017).

25. Kimberlin, D. W. et al. Effect of ganciclovir therapy on hearing in symptomatic congenital cytomegalovirus disease involving the central nervous system: A randomized, controlled trial. J. Pediatr. 143, 16-25 (2003).

26. Kimberlin, D. W. et al. Pharmacokinetic and pharmacodynamic assessment of oral valganciclovir in the treatment of symptomatic congenital cytomegalovirus disease. J. Infect. Dis. 197, 836-845 (2008).

27. Kimberlin, D. W. et al. Valganciclovir for symptomatic congenital cytomegalovirus disease. N. Engl. J. Med. 372, 933-943 (2015). 